\title{
Cálculo das recomendações de ingestão protéica: aplicação a pré-escolar, escolar e adulto utilizando alimentos brasileiros*
}

\author{
Calculation for recommendations regarding protein intake: their application to \\ children and adults taking Brazilian foods
}

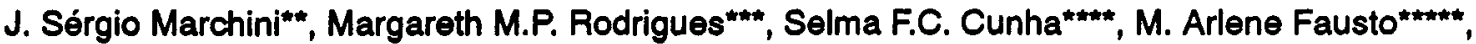 \\ Helio Vannucchi**, J.E. Dutra de Oliveira**
}

\begin{abstract}
MARCHINI, J.S. et al. Cálculo das recomendações de ingestão protéica: aplicação a pré-escolar, escolar e adulto utilizando alimentos brasileiros. Rev. Saúle Pública, 28: 146-52 1994. As recomendações de ingestão protéica variam conforme o teor de proteína, da quantidade de aminoácidos essenciais oferecidas e da digestibilidade da dieta. Em geral as recomendações protéicas tomam por base um alimento considerado padrão como o ovo ou o leite. No entanto, a nível populacional, ingere-se misturas de alimentos em quantidades e qualidades diferentes, que variam de região para região. A título de ilustração foram calculadas as recomendações de ingestão protéica para uma mistura de alimentos habitualmente usados pela população brasileira e consumida por três grupos etários diferentes: o pré escolar, o escolar e o adulto. São apresentadas 10 combinações de alimentos, todas tendo como principal fonte protéica o arroz e/ou o feijão. Observa-se que a recomendação de ingestão protéica do pré escolar, pode variar entre 1,15 a 1,77 $\mathrm{g} / \mathrm{kg}$ por dia dependendo da mistura utilizada. Discute-se também a importância da quantidade de alimentos ingeridos e a presença de outros nutrientes. Sugere-se que ao se recomendar a ingestão protéica de uma determinada mistura de alimentos sejam considerados os seguintes fatores: teor total de nitrogênio, quantidade de aminoácidos essenciais, digestibilidade, peso total da mistura e a presença de outros nutrientes.
\end{abstract}

Descritores: Proteínas na dieta. Necessidades nutricionals. Arroz. Feijão.

\section{Introdução}

A ingestão de alimentos pela população é influenciada pela disponibilidade de alimentos e por aspectos sociais, culturais, econômicos e capacidade de utilização do alimento pelo organismo ${ }^{6,7}$. Também deve ser levado em consideração que uma orientação alimentar correta

Trabalho parcialmente financiado pelo CNPq. Proces so $\mathrm{n}^{\mathrm{2}}$ 500005/92-3.

* Departamento de Clínica Médica, Faculdade de Medicina de Ribeirão Preto da Universidade de São Paulo . Ribeirão Preto, SP - Brasil

-.* Unidade Metabólica da Disciplina de Nutrologta - Hospital das Clínicas de Ribeirão Preto - Ribeirão Preto, SP - Brasil

-*.* Departamento de Clínica Médica da Faculdade de Medicina do Triângulo Mineiro - Uberada, MG - Brasil

-** Departamento de Nutrição da Universidade Federal de Ouro Preto - Ouro Preto, MG - Brasil

Separatas/Reprinrts: J.S. Marchind - Av. Bandeirantes, 3900 . 14049900 - Ribeirão Preto, SP - Brasil

Edição subvencionada pela FAPESP. Processo 94/0500-0 não pode ser eventual ou aleatória, já que os conhecimentos exigem a sua adequação e o correto fornecimento de macro e micro nutrientes ${ }^{3,16,22,30}$. De fato, a importância da alimentação orientada é um dos pontos principais no que concerne ao bem estar e adequado estado nutricional da população. Dentre os itens a se considerar em uma alimentação balanceada, baseada em uma mistura de alimentos, destacam-se as diferentes fontes protéicas. A proteína participa de processos vitais orgânicos, e constitui mais da metade do peso seco de muitos órgão ${ }^{8,14}$. Conseqüentemente, as condições relacionadas à oferta protéica consideraram os problemas nutricionais predominantes em saúde pública. Eles podem influenciar as características e padrões alimentares de determinadas regiões exprimindo aspectos socioeconômicos, políticos e culturais ${ }^{3}$.

Nos últimos 70 anos, os estudos sobre as necessidades humanas de proteina vêm sendo conduzidos em diversos países e por muitos 
grupos de especialistas $24,25,26,27,31$. Todavia, este tópico ainda permanece sob investigações, e as recomendações de proteína para populacṍes são ainda motivo de controvérsias $9,10,11$, 12,13 . Os primeiros estudos para determinação das recomendações protéicas ideais, iniciaramse por volta de $1940^{18}$. Para tanto, foi utilizada a técnica de balanço nitrogenado ${ }^{19}$. A partir daí, devido à necessidade de se encontrar a quantidade ideal de proteínas a ser oferecida em diferentes tipos de alimentação, de acordo com as características dos diversos grupos populacionais, foram criados novos métodos de avaliação. Em 1946, Block e Mitchell ${ }^{2}$ propuseram o cômputo químico para a avaliação da qualidade nutricional protéica, que é a medida da proporção de aminoácidos essenciais contidos na mesma em relação a um padrão pré-definido. $O$ uso do cômputo químico tem se mostrado útil para predizer o potencial nutricional protéico de alimentos ou da alimentação humana ${ }^{11,17}$. Recentemente, foi proposto um novo padrão de aminoácidos para o cálculo de um cômputo padrão. Este novo padrão procura demonstrar a capacidade da alimentação, em países $\mathrm{em}$ desenvolvimento, para satisfazer as necessidades humanas de aminoácidos. Em geral a alimentação de grandes contingentes populacionais no mundo tem os cereais como principal fonte protéica, e eles são deficientes em lisina. $O$ padrão sugerido é similar às recomendações internacionais de ingestão de aminoácidos para pré-escolares entre 2 a 5 anos de idade ${ }^{28,29}$.
Por outro lado, ao se fazer a recomendação de proteína para diferentes grupos populacionais ${ }^{10}$, além da composição aminoacídica da alimentação ${ }^{21}$, devem ser consideradas a quantidade total de nitrogênio e a digestibilidade da mistura protéica. Por fim, define-se como uma mistura protéica de boa qualidade ou de alto valor biológico, aquela que fornece quantidades adequadas de aminoácidos essenciais, de nitrogênio total, além de boa digestibilidade. Desta maneira, ao se determinar o valor protéico de uma mistura de alimentos deve ser levado em consideração o cômputo químico, o teor total de nitrogênio e a digestibilidade $^{13}$.

Ao lado das fontes de proteína animal, classicamente consideradas como de alto valor biológico, tem sido demonstrado que misturas de vegetais, como de um cereal e uma leguminosa, também resultam em misturas protéicas de alto valor biológico $1,4,8,23$. No Brasil a principal fonte protéica da alimentação é derivada da ingestão de arroz c feijão ${ }^{5,20}$. Esta mistura tem se mostrado adequada $\mathrm{em}$ teor nitrogenado, supre os aminoácidos essenciais e possui digestibilidade ao redor de $80 \% 26,27$.

Considerando que o arroz e feijão é uma mistura protéica largamente utilizada pela população brasileira, e, na grande maioria das vezes, o cálculo da sua quantidade protéica é feito sem levar em conta o cômputo químico e a digestibilidade das misturas de alimentos ingeridos, pretendeu-se discutir o assunto para:

Tabela 1. Alimentos que compöem as diferentes dietas estudadas.

\begin{tabular}{|c|c|c|c|c|c|c|c|c|c|c|}
\hline \multirow{2}{*}{ Alimentos (\%) } & \multicolumn{10}{|c|}{ Dietas* } \\
\hline & A & B & C & D & E & $\boldsymbol{F}$ & $\mathbf{G}$ & H & 1 & $J$ \\
\hline Arroz cozido & 100 & - & 76 & 74 & 68 & 59 & 42 & 37 & 58 & 20 \\
\hline Feijāo cozido & - & 100 & 24 & 24 & 22 & 19 & 14 & 12 & 19 & 7 \\
\hline Pāo & - & - & - & 2 & 2 & 2 & 5 & 5 & 2 & 7 \\
\hline Couve-manteiga cozida & - & - & - & - & 8 & 7 & 8 & 9 & 7 & 12 \\
\hline Laranja & - & - & - & - & - & 13 & 14 & 16 & 13 & 23 \\
\hline Came de vaca assada & - & - & - & - & - & - & - & - & 1 & 8 \\
\hline Leite pasteurizado " $\mathrm{C}$ " & - & - & - & - & - & - & 14 & 16 & - & 23 \\
\hline Ovo de galinha cozido - & - & - & - & - & - & - & 3 & 5 & - & - \\
\hline Total arroz e/ou feijāo & 100 & 100 & 100 & 98 & 90 & 78 & 56 & 49 & $\pi$ & 27 \\
\hline Total outros alimentos & 0 & 0 & 0 & 2 & 10 & 22 & 44 & 51 & 23 & 73 \\
\hline
\end{tabular}

- Teor percentual de cada alimento 
- adaptar as recomendações de protcína para a alimentação brasileira corrigida pelo cômputo químico e digestibilidade ponderal da dieta;

- calcular as recomendações protéicas de pré-cscolares, escolares cadultos reccbendo diferentes alimentos brasileiros, que incluam o arroz e feijão em diferentes proporções;

- mostrar a influência de difcrentes proporções de arroz e feijão no cálculo das recomendações.

\section{Exemplos de dietas com alimentos brasileiros}

Foram selecionados 10 diferentes tipos de combinações de alimentos para serem estudados, aqui denominadas de $\Lambda$ a J. $\Lambda$ s misturas $\Lambda$ e $B$ eram compostas exclusivamente de arro\% $\mathrm{c}$ feijão. As misturas de $C$ a J eram misturas de alimentos normalmente consumidas pela população da região de Ribeirão Preto. $\Lambda$ mistura I ć a dieta geral normalmente ofcrecida aos pacientes do IIospital das Clínicas de Ribcirão Preto. As diferentes proporções de alimentos conticlas em cada mistura de alimentos estão apresentadas na Tabela 1. Procurou-se manter a proporção de 1:1 na quantidade de proténa oferecida pelo arroz e feijão. O teor de proténa (nitrogênio) de todos os alimentos foi determinado pelo método de Kjeldhal no Laboratório de Nutiologia da Faculdade de Medicina de Ribeirão Preto. O fator de conversão de nitrogênio para proté́na para o arroz foi de 5,39, para o leite 6,38, para o pão 6,31 e para todos os demais alimentos, incluindo o feijão $6,25^{15}$.

\section{Cômputo químico}

Foram calculados a partir da composiçĩo de aminoácidos dos vários alimentos utilizados. Para o arroz e feijão utilizou-se valores previamente determinados pelo Centro de Química de Proténas/Laboratório de Nutriç̃o da Faculdade de Medicina de Ribeirão Preto ${ }^{26}$, e para os demais alimentos foram usados dados de composição de aminoácidos anteriormente publicados 15 . O cômputo químico (CQ) foi calculado a partir da seguinte fórmula:

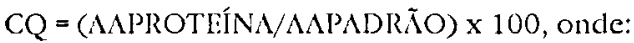

AAPROTlíNA = mg de aminóicido $\mathrm{cm}$ uma $(1) \mathrm{g}$ de proténa da dicta avialiada

A $\mathrm{PADR} \tilde{\mathrm{O}}=\mathrm{mg}$ de aminoácido no referencial conside rado13.

\section{Digestibilidade}

A digestibilidade definida como a quantidade de nitrogênio absorvida cm relação à oferecida, foi calculacla, preferencialmente, a partir de dados locais $8,26,27$. Quando não foi possível conscguir estas informações foram usadas tabelas internacionais ${ }^{13}$. Em resumo, foram os seguintes os valores de digestibilidade: alimentos de origem animal e pão $100 \%$; arroz $93 \%$; feijão $82 \%$; couve e laranja $80 \%$. Tanto no caso da digestibilidade final da dieta, como no do cômputo químico, o valor final da mistura foi obtido pela média ponderacla dos alimentos individuais e tcor total protéico da dicta ${ }^{13}$.

\section{Cálculo das recomendações}

Para o cálculo das recomendações protéicas seguiu-se as normas publicaclas em $1985 \mathrm{da}$ $\mathrm{FAO} / \mathrm{WHIO} / \mathrm{UNU}^{13}$, ou scja:

$$
\mathrm{RP}=\mathrm{PRT} \times(\mathrm{CQ} / 100) \times(\mathrm{DIG} / 100) \text {, onde: }
$$

$R P=$ Recomendaçĩo de ingestĩo protéica corrigida para uma determinada mistura de alimentos e faixa críria,

$P R T=$ Quantidade de protcína ma mistura de alimentos ofcrecida,

$\mathrm{CQ}=$ Computo químico, ou percentagem de aminoácido limitante, calculado a partir da quantidade relativa de aminó́cidos oferecidos na dicla pelos diferentes alimentos considerados, e

DIG = Digestibilidade proporcional da dieta.

\section{Recomendações de ingestão protéica}

As fórmulas dictéticas, ou conjunto de alimentos, apresentadas na Tabcla 1 , foram calculadas a partir de alimentos comumentes ingeridos pela população brasilcira ${ }^{7}$. $\Lambda$ s diclas A e B representam o arroz e feijão, isoladamente. Estas duas formulaçôes foram usadas como refercncial. A Tabcla 2 mostra o cômputo químico dessas dietas. Na maioria das dictas a lisina representou menos que $100 \%$ do padrão considerado, sendo que para o arroz puro, dieta $\Lambda$, esta percentagem foi de $76 \%$ 
e para as demais dietas $\mathrm{cm}$ torno de $92 \%$. No caso do feijão puro, dieta B, a mctionina foi o aminoácido limitante. O fato da lisina ser o aminóicido limitante na maioria das vezes cstá de acordo com os dados de dietas a base de cercais usadas $\mathrm{cm}$ outras localidades ${ }^{28}$.

A Tabela 3 apresenta os valores recomendados pela FAO/WIIO de ingestĩo protéica para pré-escolares, escolares c adultos, corrigiclos para as diferences dietas. Também são apresentados os teores protéicos, digestibilidade e cômputo químico finais. Para o cálculo desses valores foi considerada, a partir da Tabcla 1, os valores individuais para cada alimento e a proporção destes mesmos alimentos na mistura que compõe cada uma das dietas. Desta forma, por exemplo, a digestibilidade final da dicta foi proporcional a digestibilidade individual de cada alimento e a quantidade total deste alimento na dieta como um todo.

$\Lambda$ título de ilustração, estão apresentadas na Tabcla 3 várias características das dietas que suprem as recomendações protéicas para os grupos estudados (pré-escolar, escolar e adulto). Estas caractcristicas incluem o peso total da dieta, a oferta calórica total, o ferro, a vitamina C e o cálcio. $\Lambda$ o serem feitos esses cálculos não se considerou qualquer adição de gordura, água ou condimentos, como o sal de cozinha. Desta mancira os números apresentados na Tabela 4 são os resultados da análise exclusiva do conjunto de alimentos inclúclos na Tabela 1.

Tabela 2. Cômputo químico das diferentes dietas estudadas.

\begin{tabular}{|c|c|c|c|c|c|c|c|c|c|c|}
\hline \multirow{2}{*}{ Aminoácidos } & \multicolumn{10}{|c|}{ Dietas* } \\
\hline & $A$ & B & 0 & $D$ & $E$ & $F$ & $G$ & $H$ & 1 & $L$ \\
\hline Triptofano & 124 & 91 & 107 & 106 & 106 & 105 & 111 & 114 & 105 & $\$ 12$ \\
\hline Treonina & 105 & 118 & $\{11$ & 109 & 109 & 106 & 113 & 115 & 108 & 123 \\
\hline Isoleucina & 142 & 150 & 143 & 146 & $\uparrow 44$ & 106 & 153 & 157 & 145 & 123 \\
\hline Leucina & 130 & 117 & 123 & 122 & 120 & 118 & 121 & 121 & 118 & 119 \\
\hline Lisina & 67 & 124 & 96 & 93 & 91 & 90 & 92 & 93 & 92 & 125 \\
\hline Metionina + Cistina & 155 & 76 & 116 & 118 & 116 & 131 & 168 & 177 & 124 & 163 \\
\hline Fenilalanina + Tirosina & 147 & 125 & 133 & 134 & 132 & 103 & 129 & 129 & 127 & 128 \\
\hline Valina & 174 & 131 & 152 & 150 & 149 & 147 & 157 & 161 & 144 & 150 \\
\hline Histidina & 133 & 152 & 143 & 141 & $\$ 41$ & 151 & 148 & 148 & 159 & 179 \\
\hline
\end{tabular}

* Percentagem do aminoácido em relação ao padrão FAONHO/UNU ${ }^{12}$ (1985).

Tabela 3. Recomendações protéicas para o pré-escolar, escolar e adulto recebendo as dietas analisadas.

\begin{tabular}{|c|c|c|c|c|c|c|c|c|c|c|}
\hline \multirow{2}{*}{ Grupos etários } & \multicolumn{10}{|c|}{ Dietas* } \\
\hline & A & $\mathrm{B}$ & c & $D$ & $E$ & $\mathrm{~F}$ & $G$ & $\mathrm{H}$ & 1 & $L$ \\
\hline \multicolumn{11}{|c|}{ Recomendaçōes"* - g Proteína $/ \mathrm{kg} / \mathrm{dia}$} \\
\hline Pré-escolar & 1,77 & 1,77 & 1,31 & 1,34 & 1,37 & 1,38 & 1,31 & 1,29 & 1,36 & 1,15 \\
\hline Escolar & 1,59 & 1,59 & 1,18 & 1,21 & 1,23 & 1,25 & 1,18 & 1,16 & 1,22 & 1,04 \\
\hline Adulto & 1,20 & 1,20 & 0,89 & 0,92 & 0,93 & 0,95 & 0,89 & 0,88 & 0,92 & 0,79 \\
\hline \multicolumn{11}{|c|}{ Características das dietas } \\
\hline Teor protéico $\cdot g \%$ & 2,0 & 6,5 & 3,1 & 3,2 & 3,1 & 2,8 & 3,0 & 3,1 & 2,9 & 4,2 \\
\hline Disgestibilidade relativa - $\%$ & 93 & 82 & 87 & 88 & 88 & 87 & 91 & 92 & 88 & 95 \\
\hline Cômputo quimico - \% & $67^{\star \star *}$ & $76^{\star k+*}$ & $96^{\text {*** }}$ & $93^{* * *}$ & $92^{k \star k}$ & $90^{* * *}$ & $93^{* * *}$ & $93^{* \star *}$ & $92^{* * *}$ & 100 \\
\hline
\end{tabular}

- Teor percentual de cada alimento.

* Também conhecido com nivel seguro de ingestão protéica ("Safe level of dietary protein").

*** Aminoácido Vimitante = lisina.

\#*** Aminoácido limitante = metionina. 
Tabela 4. Quantidade total de alimentos, calorias, proteinas, cálcio, ferro e ácido ascórbico; com objetivo de suprir somente as recomendaçōes protéicas de pré-escolares, escolares $\theta$ adultos.

\begin{tabular}{|c|c|c|c|c|c|c|c|c|c|c|}
\hline \multirow{2}{*}{ Quantidades } & \multicolumn{10}{|c|}{ Dietas* } \\
\hline & A & B & C & $D$ & E & $\mathbf{F}$ & $\mathbf{G}$ & $\mathrm{H}$ & 1 & $J$ \\
\hline \multicolumn{11}{|c|}{ Pré-escolar - sexo masculino $20 \mathrm{~kg}$} \\
\hline Quantidade total do alimento ingerido - $g$ & 1.770 & 544 & 856 & 829 & 883 & 1.023 & 780 & 840 & 957 & 548 \\
\hline Proteinas totais - 9 & 35 & 35 & 26 & 27 & 27 & 28 & 26 & 26 & 27 & 28 \\
\hline Calorias totais & 1.929 & 635 & 948 & 949 & 965 & 1.025 & 847 & 813 & 955 & 510 \\
\hline Teor de cálicio - mg & 177 & 272 & 166 & 167 & 204 & 273 & 377 & 391 & 256 & 297 \\
\hline Teor de ferro - mg & 16 & 15 & 11 & 11 & 11 & 12 & 8 & 8 & 11 & 5 \\
\hline Ácido ascórbico - mg & 0 & 0 & 0 & 0 & 22 & 100 & 96 & 95 & 98 & 96 \\
\hline \multicolumn{11}{|c|}{ Escolar - sexo masculino $35 \mathrm{~kg}$} \\
\hline Quantidade total do alimento ingerido - $g$ & 2.780 & 855 & 1.350 & 1.333 & 1.407 & 1.580 & 1.382 & 1.322 & 1.502 & 865 \\
\hline Proteinas totais - $g$ & 56 & 56 & 41 & 42 & 43 & 44 & 41 & 41 & 43 & 36 \\
\hline Calorias totais" - kcal & 3.030 & 997 & 1.496 & 1.525 & 1.541 & 1.576 & 1.332 & 1.280 & 1.494 & 804 \\
\hline Teor de cálcio - mg & 278 & 427 & 262 & 267 & 325 & 417 & 591 & 617 & 412 & 470 \\
\hline Teor de ferro - mg & 25 & 23 & 18 & 18 & 18 & 18 & 13 & 12 & 17 & 7 \\
\hline Ácido ascórbico - mg & 0 & 0 & 0 & 0 & 35 & 158 & 152 & 149 & 155 & 152 \\
\hline \multicolumn{11}{|c|}{ Adulto, sexo masculino, $70 \mathrm{~kg}$} \\
\hline Quantidade total do alimento ingerido $\cdot \boldsymbol{g}$ & 4.200 & 1.292 & 2.009 & 2.013 & 2.100 & 2.375 & 2.077 & 1.887 & 2.221 & 1.317 \\
\hline Proteinas totais $-\mathfrak{g}$ & 84 & 84 & 62 & 62 & 65 & 66 & 62 & 57 & 64 & 55 \\
\hline Calorias totais"* $-\mathrm{kcal}$ & 4.578 & 1.512 & 2.236 & 2.311 & 2.304 & 2.238 & 1.950 & 1.811 & 2.236 & 1.221 \\
\hline Teor de cálcio - mg & 420 & 648 & 398 & 408 & 513 & 600 & 897 & 881 & 594 & 727 \\
\hline Teor de ferro - mg & 38 & 35 & 27 & 27 & 28 & 26 & 19 & 17 & 25 & 11 \\
\hline Acido ascórbico - mg & 0 & 0 & 0 & 0 & 66 & 225 & 228 & 228 & 225 & 228 \\
\hline
\end{tabular}

- Teor percentual de cada alimento.

* Alimento sem adiçāo de gordura.

\section{Comentários}

As recomendações de ingestão protéica têm sido baseadas em um alimento único que tenha: boa digestibilidade, todos os aminoácidos essenciais e nitrogênio suficiente para síntese dos aminoácidos não-essenciais. Em geral, a proteína do ovo ou da caseína são consideradas adequadas ${ }^{12,13}$. No entanto, essas condições nem sempre são conseguidas quando se estuda a alimentação típica de diferentes populações. Muitas vezes estas populações ingerem uma mistura de alimentos, com digestibilidade e cômputo químico diferentes do padrão ${ }^{12,13}$. Portanto, ao se recomendar uma determinada ingestão protéica é necessário corrigir a quantidade de proteína ingerida, em relação à quantidade de nitrogênio total, teor de aminoácidos essenciais e digestibilidade, relacionados à uma fonte protéica padrão ${ }^{13,28,29}$. Basicamente todas as dietas apresentadas, com exceção da $\mathrm{A} \mathrm{e}$ $B$, preenchem as necessidades dos aminoácidos essenciais, porém nem sempre de energia ou de outros nutrientes (Tabela 4). Porém, o objetivo proposto do presente estudo foi o de sugerir a maneira mais adequada de se calcular a oferta protéica. Utilizando-se a metodologia aqui proposta, poderá ser calculada a sua oferta protéica real, baseada em uma mistura de alimentos (como farinha, inhame, e outros) ou em um alimento específico.

Em relação ao teor de aminoácidos essenciais, quando a alimentação é rica em cereais, a lisina é quase sempre o aminoácido limitante. No entanto, a utilização isolada do cômputo químico nem sempre é adequada pois os alimentos têm percentagem de absorção diferentes, que podem alterar significativamente sua 
utilização pelo organismo.A correção simples da recomendação de ingestão protéica padrão pelo cômputo químico superestima, em geral, a capacidade de uma refeição completa atingir as recomendações protéicas. Desta forma, características próprias das proteínas alimentares, diferentes fatores dietéticos (por exemplo, fibras e polifenóis) e reações químicas que alteram a degradação protéica por processos digestivos influenciam, diminuindo ou aumentando, a digestibilidade da fonte protéica ${ }^{13}$. Observase, portanto (Tabela 3), que a ingestão recomendada de proteína, para qualquer uma clas trĉs faixas etárias estudadas, varia consideravelmente nas diferentes dietas. Veja-se, por exemplo, que para o escolar a ingestão de proteína varia de 1,04 a $1,59 \mathrm{~g} / \mathrm{kg}$, fato que pode recomendar ingestões significativamente diferentes em certos programas de alimentação como a merenda escolar. A tabela 4 mostra que para esses escolares, a quantidade total de alimento ingerida variaria entre 855 a $2.780 \mathrm{~g}$, conforme a mistura de alimentos utilizados (Tabcla 1). Por outro lado, também é pouco provável que um adulto ingira mais de 4 quilos de arroz diariamente para satisfazer suas necessiclades protéicas. Cálculos semelhantes podem ser feitos em rclação à oferta calórica total (Tabela 4).

Além do peso, quantidade total da alimentação oferecida, a presença de outros nutrientes também deve ser considerada (Tabcla 4). Novamente, a título de ilustração, foram calculadas para as diferentes dietas os teores de cálcio, ferro e ácido ascórbico. Observa-se, desta maneira, que muitas vezes não foi possivel suprir as necessidades desses três nutrientes, apesar de se ter atingido as recomendações de proteína. Por outro lado, as mesmas considerações poderiam ser feitas em relação à ingestão total de energia. Apesar da aparente adequação protéica, mesmo considerando o teor de aminoácidos e a digestibilidade, se a oferta fosse exclusiva dos alimentos propostos, nos exemplos citados, poder-se-ia estar fornecendo uma quantidade inadequada de energia. Assim sendo, apesar da formulação $J$ (Tabela 4) estar fornecendo uma quantidade aparentemente adequada de proteína, ela fornece quantidade inadequada de energia, logo inadequada quanto a oferta protéica. Este observação reforça o fato de que as recomendações internacionais de proteína de. vem ser corrigidas por diversos fatores importantes e não simplesmente ofereciclas como números absolutos $\mathrm{e}$ isolados.

Conclui-se, desta maneira, que ao se fazer a recomendação de ingestão protéica, a partir de uma mistura de alimentos, deve-se: 1) consiclerar a mistura e a proporcionalidade da proténa dos alimentos que a compõe; 2) corrigir os resultados pela digestibiliclacle e cômputo químico; 3) vcrificar se a quantidade total de alimentos a ser oferccida é factível; 4) adequar a dieta quanto à presença dc outros nutrientes, para que se forneça quantidades adequadas de encrgia, proteína, minerais e vitaminas em quanticlades adequadas ${ }^{12,13}$.

MARCIIINI, J.S. et al. [Calculation for recommendations regarding protein intake: their application to children and adults taking Brazilian foods]. Rev. Saúde Pública, 28: $146-52,1994$. The recommendations for protein consumption depend on the essential amino acid and total nitrogen content of a dict, and food digestibility. International recommendations are based on cgg or milk proteins. However, populations eat different food mixtures. Binzilians use rice and beans as their main protein food source. This study presents different Brazilian diets, with variable amount of rice and beans. The results show that for each dict there is a different amount of protein recommended. Pre-school children, for example, must receive from 1.15 to 1.77 $\mathrm{g} /$ protein/day, depending on the mixture of their dietary protein intake. Besides the diet protein's quality and quantity, the total food intake and presence of other essential nutrients, such as iron, calcium and vitamin $C$ has also to be considered. The correct protein recommendation with respect to a diet or a mixture of food, should take into consideration: digestibility, total nitrogen, essential amino acids, presence of others nutrients and weight os food consumed.

Keynuords: Dictary proteins. Nutritional requirements. Rice. Bean.

\section{Referências Bibliográficas}

1. ATINMO, T.; EGUN, G.; MBOFUNG, C.M. Long term cvaluation of the adequacy of habitual dicts to provide protein needs of adult Nigerian men. Bi:J.Nutr, 60:459-66, 1988.

2. BLOCK, R.J. \& MITCIIELL, II.II. The correlation of amino acid compositon of protein with their nutritive value. Nutr:Abst.Rev.,16:249-78, 1946.

3. BRICKER, M.L. \& SMITII, J.M. $\Lambda$ study of the endogenous nitrogen output of college women, with particular reference to use of the creatinine output in the calculation of the biological values of the protein of egg and sunllower seed flour.J.Nutr.,44:553. 73,1951 . 
4. CHAVEZ, J.F. \& PELILE1T, P.L. Protein quality of some representative Latin America diets by rats biossay. J. Nutr:, 106:792-801, 1976.

5. DUTRA DE OLIVEIRA J.E. Valor nutritivo de proténas alimentares. Estudo metabólico rcializado cm crianças desnutriclas. Ribeirão Preto, 1962. ['T'ese de Livre Docência -Faculdade de Medicina de Ribeirão Preto, USP].

6. DUTRA DE OLIVEIRA, J.E. Malnutrition in developing countries: the challenges to and the responsability of the expert. Proc. Nutri. Soc. India, 112:897-907, 1991.

7. DUTRA DE OLIVEIRA, J.E; SANTOS, A.C.; WILSON,E.D. Nutrição básica. São Paulo, Editora Sal * vier, 1989.

8. DUTRA DE OLIVEIRA. J.E. \& VANNUCCII, II. The protein requirement of Brazilian rural works studics with a rice and a bean a dict.In: Rand, W..M. Proteinenergy requirements of aleveloping countries:results of international research.'Tokio, Unitcd University, 1983.p.98-114.

9. FOOD AND AGRICULIURE ORGANIZATION/WORLD HEALTH ORGANIZATION. Protein quality evaluation: preliminar report of a joint. WAO/WhO expert consullation. Washington, D.C., PAONWIO, 1989.

10. FOOD AND AGRICULTURE ORGANIZATION/NORID IELLTII ORGANIZATION. Protein quality evalua. tion: report of a joint FAO/WIIO expert consullation Group. Rome, FAO/WTIO, 1990.

11. HEGSTED, D.M. Assessment of protein quality. In: Nattional Research Council Committec on Amino Acids. Improvement of protein nutritive. Washing ton, D.C., National Academy of Science, 1974.p.6.188.

12. JOINT FAO $N$ WIO AD IIOC EXPERT COMMII"ITE ON ENERGY AND PROTEIN RLQUIRIMENTS, ROme, 1971. Report, Geneva, World Ilealth Organizattion, 1973. (WHO. Techinical Report Scrics, 522).

13. JOINT FAO/WHO/UNU EXPERT CONSULTATIION ON ENERGY AND PROTEIN REQUIREMENTS, Rome, 1981.Report.Geneva, World IIealth Organization, 1985.(WHO-Technical Report Series, 721).

14. LEHNINGER, A.L. Principios de bioquímica. Sĩo Paulo, Editora Sarvier, 1984.

15. LENTNER, L. Units of measurements, body fluids, compositon of body, nutrition. Basle, Ciba Geigy Limited, 1981 .

16. NATIONAL RESEARCII COUNCIL. Committee on Amino Acids.Improvement of protein nutritive. Washington, D.C., National Academy of Scicnces, 1974.

17. PELLET T, P.L. \& YOUNG, V.R. Nutritional evaluation of protein foods. Tokio, 1980. (Publication number WIITR/UNUP-129).
18. ROSE, W.C. The nutritive signilicance of the amino acids.Plysiol. Rev, 18:109-13, 1938

19. ROSE, W.C. The amino acid repuirements of adult mant Nutr: Abst.Rev., 27-631-47. 1957.

20. SAN'IOS, J.E.; IIOWE, J.M.; DUARIE, F.A.M.; DUTRA DE OLIVI:HRA, J. I. Relationship between the nutritional efficacy of a rice and bean diet and energy intake in preschool childern. Am.J. Clin. Nutr, 32:15:11-4,1979).

21. SARWAR, G. CIIRISILNSEN, D.A.: IINLAYSON, A.J. IRIEDMAN, M. ; HACKLER,L.R.; MLICKLNZIE, S.L.; PLIIEYIT, P.I.; TRACIIUCK, R. Intcr-and-intra-labolatory variation in amino acid analysis of lood protcins.J.Iood Sci, 48:526-31, 1983 .

22. SCRIMSIIAW', N.S.; PLRERA, W.D.A.; YOUNG, V.R. Protein requirements of man: obligatory urine and fecal nitrogen losses in clderly women J.Nutr, 106:66570,1976 .

23. TORUN, B. Protcinas y aminoatcidos, chatacteristicas y satisfacion de requirementos con dictas latinoamericanas.Arch latinoam. Nuth, 38:183-505, 1988.

24. UAUY, R.;SCRIMSILIW, N.S.; YOUNG, V.R. Iluman prolein requirements: Nitrogen balance response to graded levels of egg protein in elderly men and women.AMJ. Clin. Null:, 31:779-85, 1978.

25. UNAMUNO, M.R.D.L.; DU'TRA DEOLIVEIRA, J.E.; VANNUCCHI, HI, MARCIIINI. J.S. Protcin requitement assessment of elderly men on rice and beans diet. Nulr: Ros., 11:1199-57, 1991 .

26. VANNUCCIII, H.; DUARTL, R.M.I.; DUTRA E OLIVEIRA, J.E. Nutritive valuc of at rice and bean based diet for agricultural migrant workers in Southern Brazil.Nuti:Rep.Imt, 24:129-34, 1981 .

27. VANNUCCII,H.; DUAR'TT,R.M.F,; DUTRA DE OLIVEI$\mathrm{RA}$, J.E. Studies on the protein requitements of Barzilian rural workers ("Bóias-Frias") given a rice and bean dict.Int.f Vilamin. Res., 53:338-11́, 1983.

28. YOUNG, V.R.\& PLELIIIYL'P.L.Cutrent concepts concerning indispensable amino acids needs in adults and their implications for international nutrition plan. ning. Food Nutl:Bull, 12:289-300, 1990.

29. YOUNG, V.R. \& PELLIEl'T, P.L.Protcin cvaluation, amino acid scoring and Food and Druty Administration's proposed food labeling regulations: issues \& opinions in mutrition J. Nuff., 121:145-50,1991.

30. YOUNG, V.R. \& SCRINSHAW, N.S. Lindogenous nitrogen metabolism and plasma imino acids in young adults given a "protein-fiec" diet.Br:J.Nutr, 22:9 20, 1968 .

31. YOUNG, V.R. \& SCRIMSIIAW, N.S. I Iuman protein and amino acid metabolism and requircments in relation to protein quality. In: Bodwell, C. E. Evaluation of proleins for humans. West port, AVI Publishing Co., 1977.p. 11-54.

Recebido para publicação em 1.7.1993. Reapresentado em 16.12.1993.

Aprovado para publicaşão em 28.2.1994 